\title{
How changes in job demands and resources predict burnout, work engagement, and sickness absenteeism
}

\author{
WILMAR B. SCHAUFELI ${ }^{1 *}$, ARNOLD B. BAKKER ${ }^{2}$ \\ AND WILLEM VAN RHENEN ${ }^{3}$ \\ ${ }^{1}$ Department of Psychology, Utrecht University, Utrecht, The Netherlands \\ ${ }^{2}$ Institute of Psychology, Erasmus University Rotterdam, Rotterdam, The Netherlands \\ ${ }^{3}$ Department of Occupational Health, ArboNed, Utrecht, The Netherlands
}

\begin{abstract}
Summary The present longitudinal survey among 201 telecom managers supports the Job DemandsResources (JD-R) model that postulates a health impairment process and a motivational process. As hypothesized, results of structural equation modeling analyses revealed that: (1) increases in job demands (i.e., overload, emotional demands, and work-home interference) and decreases in job resources (i.e., social support, autonomy, opportunities to learn, and feedback) predict burnout, (2) increases in job resources predict work engagement, and (3) burnout (positively) and engagement (negatively) predict registered sickness duration ("involuntary" absence) and frequency ("involuntary" absence), respectively. Finally, consistent with predictions results suggest a positive gain spiral: initial work engagement predicts an increase in job resources, which, in its turn, further increases work engagement. Copyright (C) 2009 John Wiley \& Sons, Ltd.
\end{abstract}

\section{Introduction}

Virtually all models on occupational health and well-being focus exclusively on job stress and the resulting strain, thereby neglecting the potentially positive effects of work such as engagement. Hence, the recent call for more balanced approaches that include job strain as well as betterment of employees (Bakker \& Schaufeli, 2008; Luthans, 2003; Wright, 2003) does not come as a surprise. The Job Demands-Resources (JD-R) model is an example of such a balanced approach that seeks to explain negative (burnout) as well as positive (work engagement) aspects of well-being by linking it to a strain and motivational process, respectively (Bakker \& Demerouti, 2007). The current study has three innovative features. First, previous JD-R studies did not examine the causal (and reversed causal) effects of burnout/engagement on job demands/resources. A second distinct feature of our study is that

* Correspondence to: Wilmar B. Schaufeli, Department of Psychology, Utrecht University, Heidelberglaan 1, Utrecht 3508 TC, The Netherlands. E-mail: w.schaufeli@uu.nl 
we investigate the dynamic nature of the JD-R model by focusing on so-called loss and gain cycles that may result from an accumulation of job demands (and subsequent burnout) and job resources (and subsequent engagement), respectively. Third, we integrate company registered sickness absenteeism into the JD-R model by differentiating between "involuntary" and "voluntary" sickness absence as measures by absence duration and absence frequency, respectively (see also Bakker, Demerouti, De Boer, \& Schaufeli, 2003). Being a behavioral indicator of employee strain, the former is expected to play a role in the strain process, whereas the latter is an indicator of employee motivation and therefore plays a role in the motivational process.

\section{The job demands-resources model}

The Job Demands-Resources (JD-R) model is a heuristic and parsimonious model that specifies how job strain (burnout) and betterment (work engagement) may be produced by two specific sets of working conditions that can be found in every organizational context: job demands and job resources. The former are "the things that have to be done" (Jones \& Fletcher, 1996, p. 34) and refer to those physical, social, or organizational aspects of the job that require sustained physical and psychological (i.e., cognitive or emotional) effort, and are therefore associated with certain physiological and psychological costs (Demerouti, Bakker, Nachreiner, \& Schaufeli, 2001). Although job demands are not necessarily negative, they may turn into job stressors when meeting those demands requires high effort from which the employee has not adequately recovered (Meijman \& Mulder, 1998; Sonnentag \& Zijlstra, 2006). While Karasek's (1979) influential Demands-Control (DC) model—at least in its original form - uses a rather restricted definition of job demands that are mainly quantitative in nature (e.g., work overload and time pressure), the JD-R model expands this view by including those demanding characteristics of the working environment that are unique to the organization under study. For instance, the current study was carried out among managers who-in addition to quantitative demands - are also faced with emotional demands and inter-role conflict between work and family (Burke, 1988).

The second set of working conditions concerns the extent to which the job offers resources to individual employees. They refer to those physical, social, or organizational aspects of the job that may: (1) reduce job demands and the associated physiological and psychological costs, (2) be functional for achieving work goals, or (3) stimulate personal growth, learning, and development (Demerouti, Bakker, Nachreiner, et al., 2001). In the current study, we included autonomy, social support, performance feedback, and opportunities to learn, not only because of their inherent motivational qualities but also because a lack of these job resources has been associated with managerial stress (Burke, 1988). Moreover, opportunities to learn are deemed important because managers have a particularly strong need for learning, development, and career advancement (Tharenou \& Conroy, 1994).

The central tenet of the JD-R model is that, irrespective of the occupation involved, job demands may evoke a strain or health impairment process, whereas job resources induce a motivational process (Bakker \& Demerouti, 2007; Schaufeli \& Bakker, 2004a). The strain process is illuminated by Hockey's $(1993,1997)$ compensatory regulatory-control model. According to this model, employees under stress face a trade-off between the protection of their performance goals (benefits) and the mental effort that has to be invested in order to achieve these goals (costs). When job demands increase, regulatory problems occur in the sense that compensatory effort has to be mobilized to deal with the increased demands whilst maintaining performance levels. This extra compensatory effort is associated with physiological and psychological costs such as increased sympathetic activity, fatigue, and irritability. Continuous mobilization of compensatory effort drains the employee's energy and might 
therefore lead to burnout, ill-health, (Hockey, 1997; Ursin, Murison, \& Knardahl, 1983), and eventually absenteeism.

The second, motivational process is driven by the availability of job resources, which by definition, play a motivational role because they foster employees' growth, learning and development or because they are instrumental in achieving work goals. In the former case, job resources fulfill basic human needs, such as the needs for autonomy, relatedness, and competence as postulated in self-determination theory (Deci \& Ryan, 2000; Ryan \& Frederick, 1997). For instance, proper feedback fosters learning, thereby increasing job competence, whereas decision latitude and social support satisfy the needs for autonomy and the need to belong, respectively. In the latter case, the motivational role of job resources might be explained by the effort-recovery approach (Meijman \& Mulder, 1998). According to this approach, work environments that offer abundant resources foster the willingness of employees to dedicate their efforts and abilities to the work task. In such environments, it is likely that the task will be completed successfully and that the work goal will be attained. For instance, supportive colleagues and performance feedback increase the likelihood of being successful in achieving one's work goals. Hence, job resources are likely to foster work engagement through a motivational process that satisfies basic needs for autonomy, relatedness, and competence and that increases the likelihood of attaining one's work goals.

The two most often studied negative and positive outcomes in the JD-R model are burnout and work engagement, respectively. Burnout is usually defined as a syndrome of exhaustion, cynicism, and lack of professional efficacy (Maslach, Schaufeli, \& Leiter, 2001). However, accumulating evidence indicates that lack of professional efficacy plays a divergent role as compared to exhaustion and cynicism (see e.g., Lee \& Ashforth, 1996; Leiter, 1993; Schaufeli \& Salanova, 2007a) that are considered the essence or "core" of the burnout syndrome (Green, Walkey, \& Taylor, 1991; Schaufeli \& Taris, 2005). Work engagement is defined as a positive work-related state of mind that is characterized by vigor, dedication, and absorption (Bakker \& Schaufeli, 2008; Schaufeli \& Salanova, 2007b). However, recent research suggests that vigor and dedication constitute the core of engagement, whereas absorption seems to be related to the concept of flow (Csikszentmihalyi, 1990) and plays a different role compared to both other engagement dimensions (Salanova, Llorens, Cifre, Martínez, \& Schaufeli, 2003). Flow refers to a short-term state of optimal experience - also outside the realm of work - that is characterized by focused attention, clear mind, mind and body unison, effortless concentration, complete control, distortion of time, and intrinsic enjoyment. Burnout and work engagement are distinct, yet negatively correlated concepts (Maslach, Schaufeli, \& Leiter, 2001). More specifically, burnout is characterized by a combination of low energy (exhaustion) and low identification (cynicism), whereas work engagement is characterized by the opposite: a combination of high energy (vigor) and high identification (dedication). Hence, work engagement and job burnout are a function of two underlying psychological dimensions dubbed energy and identification with one's work (González-Romá, Schaufeli, Bakker, \& Lloret, 2006).

In the current study we introduce sickness absenteeism as an additional element in the JD-R model. Although sickness absence is a complex phenomenon that is influenced by a host of social, organizational, and personal factors (for a recent review, see Dekkers-Sanchez, Hoving, Sluiter, \& Frings-Dresen, 2008), it is assumed that there are two explanations for employees' decisions to report themselves sick (Bakker, Demerouti, De Boer, et al., 2003; Johns, 1997). First, employees may be absent because they want to withdraw from aversive work circumstances. Using this withdrawal hypothesis it has been found that employees who are low in job satisfaction and organizational commitment are more frequently absent than those who are more satisfied and committed (e.g., Farrell \& Stam, 1998; Mathieu \& Kohler, 1990; Sagie, 1998; Stansfeld, Head, \& Ferrie, 1999). This agrees with the notion of "voluntary" absenteeism because it involves an escape from, or even protest against 
poor or aversive work circumstances (Chadwick-Jones, Nicholson, \& Brown, 1982). "Voluntary" absenteeism is usually operationalized as absence frequency, i.e., the number of spells or times an employee has been absent during a particular period, regardless of the length of each of those spells (Steel, 2003). A second explanation for absenteeism is that absence behavior is a reaction to distress caused by job demands. This explanation stipulates that absenteeism may be used as a coping mechanism to deal with stressful job demands and that it is not merely a behavioral reaction to dissatisfaction (Kristensen, 1991). Using the stress reaction hypothesis, it has been found that job stressors such work overload (Dwyer \& Ganster, 1991), high emotional demands (Bakker, Demerouti, \& Schaufeli, 2003b), and work-home conflict (Goff, Mount, \& Jamison, 1990), as well as elevated burnout levels (Iverson, Olekalns, \& Erwin, 1998; Parker \& Kulik, 1995) are associated with higher absence rates. This agrees with the notion of "involuntary" absenteeism because it involves the inability to perform work tasks (Chadwick-Jones et al., 1982). "Involuntary" absence is usually operationalized as absence duration, i.e., the total length of time an individual has been absent over a specified period regardless of the number of absence spells (Steel, 2003). Accordingly, in terms of the JD-R model it seems that "voluntary" sickness absence is associated with the motivational process, whereas "involuntary" sickness absence is associated with the strain process. More particularly, like satisfied and committed employees, engaged employees are not likely to report themselves ill, whereas those suffering from job strain (burnout) are likely to be unable to go to work. So based on the JD-R model, different predictions can be made about different kinds of absenteeism. Indeed, an earlier study that used a modified JD-R framework which included organizational commitment instead of work engagement, found that high job demands (and not lacking job resources) were related-via burnout - to absence duration, whereas lacking job resources (and not high job demands) were related — via commitment — to absence frequency (Bakker, Demerouti, De Boer, et al., 2003).

In conclusion, according to the JD-R model, the two sets of working conditions evoke different processes: (1) a strain process in which high job demands (e.g., work overload, emotional demands, work-home conflict) deplete employees' mental energy and thus may produce burnout (exhaustion and cynicism) and "involuntary" sickness absence; (2) a motivational process in which sufficient job resources (e.g., autonomy, performance feedback, social support, and opportunities for learning) foster employee motivation and thus may produce work engagement (vigor and dedication) and reduce "voluntary" sickness absence.

\section{Evidence for the JD-R model}

So far, the main assumptions of the JD-R model have been confirmed in cross-sectional studies (for a review see Bakker \& Demerouti, 2007), but an integral longitudinal test still stands out. First, it appears that job demands and job resources can be empirically distinguished and that they are weakly to moderately negatively correlated (e.g., Bakker, Demerouti, De Boer, et al., 2003; Bakker, Demerouti, Taris, Schaufeli, \& Schreurs, 2003; Demerouti et al., 2001a; Schaufeli \& Bakker, 2004a). Second, as far as the strain process is concerned, results convincingly show that job demands are positively related to burnout (Bakker, Demerouti, De Boer, et al., 2003; Bakker, Demerouti, \& Euwema, 2005; Demerouti, Bakker, De Jonge, Janssen, \& Schaufeli, 2001; Hakanen, Bakker, \& Schaufeli, 2006; Llorens, Bakker, Salanova, \& Schaufeli, 2006; Schaufeli \& Bakker, 2004a) and particular to its hallmark exhaustion (Bakker, Demerouti, De Boer, et al., 2003; Bakker, Demerouti, \& Verbeke, 2004; Demerouti, Bakker, Nachreiner, et al., 2001; Lewig \& Dollard, 2003). Third, and in accordance with the burnout literature (Halbesleben \& Buckley, 2004; Lee \& Ashforth, 1996; Schaufeli \& Enzmann, 1998; Neveu, 2007), poor job resources are also related to burnout - particularly cynicism-albeit that this relationship is generally weaker than with job demands (Bakker, Demerouti, Taris, et al., 2003; Bakker et al., 2004, 
2005; Hakanen et al., 2006; Lewig \& Dollard, 2003; Llorens et al., 2006; Schaufeli \& Bakker, 2004a). Theoretically speaking this agrees with the contention that the underlying dimensions of burnout are affective (exhaustion) and motivational (cynicism) in nature (González-Romá et al., 2006). Fourth, there is evidence for the mediating role of burnout in the relationship between job demands and various indicators of physical or mental ill-health (Bakker, Demerouti, De Boer, et al., 2003; Bakker, Demerouti, \& Schaufeli, 2003; Hakanen et al., 2006; Llorens et al., 2006; Schaufeli \& Bakker, 2004a). Hence, based on the propositions of the JD-R model that are supported by cross-sectional results, we formulate:

Hypothesis 1: Job demands and job resources predict future burnout. More specifically, after controlling for baseline burnout, increases in job demands and decreases in job resources predict future burnout.

Fifth, as far as the motivational process of the JD-R model is concerned, it has been consistently found that job resources (and not job demands) are positively related to work engagement (Hakanen et al., 2006; Llorens et al., 2006; Schaufeli \& Bakker, 2004a). Recently, using a 2-year longitudinal study, Mauno, Kinnunen, and Ruokolainen (2007) showed that between $4 \%$ and $10 \%$ of additional variance in engagement dimensions was explained by base-line levels of job resources, after controlling for baseline job demands. Sixth, there is evidence for the mediating role of work engagement in the relationship between job resources and various indicators of organizational commitment (Hakanen et al., 2006; Llorens et al., 2006; Schaufeli \& Bakker, 2004a). Hence, based on the propositions of the JD-R model that are supported by cross-sectional results, we formulate:

Hypothesis 2: Job resources predict future levels of work engagement. More specifically, after controlling for baseline work engagement, increases in job resources predict future work engagement.

\section{Sickness absenteeism and the JD-R model}

As argued before, "voluntary" and "involuntary" absenteeism play a role in the motivational process and the strain process of the JD-R, respectively. Although many research findings indicate that motivational variables (i.e., job satisfaction) are more strongly related to "voluntary" absenteeism (i.e., absence frequency) than to "involuntary" absenteeism (i.e., time lost) these results are not entirely unequivocal (Steel, 2003). Nevertheless, it seems that different processes exist that lead to either long or to less frequent absenteeism (Bakker, Demerouti, De Boer, et al., 2003; Johns, 1997; Kohler \& Mathieu, 1993). Thus, we formulated the following two hypotheses:

Hypothesis 3: Burnout predicts future absence duration (but not absence frequency): the more burned-out, the longer the absence spells.

Hypothesis 4: Engagement predicts future absence frequency (but not absence duration): the more engaged, the fewer future absence spells.

\section{Loss and gain cycles}

Previous research has not only provided evidence for causal relationships between job demands and burnout, and between job resources and engagement but also reciprocal effects. For instance, Demerouti, Bakker, and Bulters (2004) studied the strain process and found that in addition to normal causation, exhaustion predicted future work pressure. Such reciprocal relationships are not uncommon. 
In their review of longitudinal studies on organizational stress, Zapf, Dormann, and Frese (1996) found reversed effects in six out of sixteen studies. Also more recent studies provide additional evidence for reciprocal causation, for instance between job characteristics (job control, job complexity, supervisor support, work pressure, and boundary spanning) and burnout, particularly exhaustion (De Lange, Taris, Kompier, Houtman, \& Bongers, 2004).

Reciprocal relationships between job demands and burnout are compatible with the notion of loss cycles as proposed by conservation of resources (COR) theory (Hobfoll \& Shirom, 2000). According to COR-theory, people strive to obtain, retain, and protect things they value, which are called resources and include material objects (e.g., a computer), social conditions (e.g., favorable job characteristics), personal characteristics (e.g., self-efficacy), and energies (e.g., vigor). Hobfoll and Shirom (2000) have argued that those individuals who do not have access to strong resource pools are more likely to experience increased resource loss (loss cycle), whereas those with strong resource pools will invest resources for future resource gains (gain cycle).

Testing this dynamic nature of their COR-model, Hobfoll, Johnson, Ennis, and Jackson (2003) found indeed that both loss and gain of material, social and personal resources were related to changes in depressive mood and anger. Specifically, resource loss was related to increased emotional distress (depressive mood and anger), whereas resource gain was related to decreased distress.

Recently, Shirom, Melamed, Toker, Berliner, and Shapira (2005) applied the notions of COR-theory to burnout. They argued that when individuals experience job stress (i.e., when resources are lost or threatened, or when resource investments do not reap the anticipated return) they respond by attempting to limit the impact of that stress through energy conservation. This in itself requires additional resource expenditure (e.g., spending more time and effort in stress management) that might further deplete the employee's energy backup and contribute to burnout. In other words, in trying to cope with job stress and protect one's resources, other resources have to be invested which carries the risk of burning-out. This, in its turn, will perpetuate recourse loss. Shirom et al. (2005, p. 289) concluded that: “. . .burnedout individuals risk entering an escalating spiral of losses, cumulating in an advanced stage of burnout." Hence, we formulate:

Hypothesis 5: Baseline burnout predicts future burnout via an increase in job demands and a decrease in resources (loss cycle).

In contrast, according to COR-theory gaining resources increases the individual's resource reservoir, which makes it more likely that additional resources will be acquired. Indeed, Llorens, Schaufeli, Bakker, and Salanova (2007) observed in an experimental study that task resources (i.e., time control and method control) increased engagement (via self-efficacy), which, in its turn, increased task resources (again via self-efficacy). Thus, evidence was found for a gain cycle: task resources $\rightarrow$ engagement $\rightarrow$ task resources, whereby self-efficacy played a mediating role. Furthermore, results from a recent longitudinal field study Salanova, Bakker, and Llorens (2006) on flow also suggests a similar cycle: flow-measured as a combination of absorption, intrinsic work motivation, and work enjoyment - fosters job recourses (in terms of organizational culture) that in turn increase flow experiences.

The finding that positive emotional states (work engagement and flow) increase job resources is consistent with Broaden-and-Build theory (Fredrickson, 2001, 2003). Although this theory is about emotions instead of engagement and about personal resources instead of job resources, striking parallels exist. For instance, a recent study showed that positive emotions are involved in the motivation process of the JD-R model (i.e., mediate the relationship between resources and engagement), whereas negative emotions are involved in the strain process (i.e., mediate the relationship between job demands and burnout) (Schaufeli, \& Van Rhenen, 2006). According to Fredrickson (2001), positive emotions 
broaden people's momentary thought-action repertoires and build their enduring personal resources. Her theory suggests that positive emotions broaden people's modes of thinking and action, which over time builds their enduring resources. These resources, in their turn, function as reserves that can be drawn on later to help people thrive, thus triggering a gain cycle toward greater emotional well-being and more resources. The existence of such gain cycles at the workplace that are fueled by positive emotions is suggested by the results of two studies by Staw and his colleagues (Staw, Sutton, \& Pellod, 1994; Wright \& Staw, 1999). Both studies showed that positive emotions predict future improvements in social support from supervisors and coworkers, future improvements in supervisor evaluations, and future pay increases. Hence, individuals who at initial assessment experience positive emotions had, over time, transformed themselves into more effective and socially integrated employees who could draw upon larger resource pools (i.e., social support, money). As outlined above, the JD-R model predicts that increases in job resources fosters employee motivation and concomitant work engagement. Therefore, applied to our study, we formulate:

Hypothesis 6: Baseline work engagement predicts future engagement via an increase in job resources (gain cycle).

The hypothetical research model of our study is graphically displayed in Figure 1, whereby the numbers in the figure refer to the hypotheses.

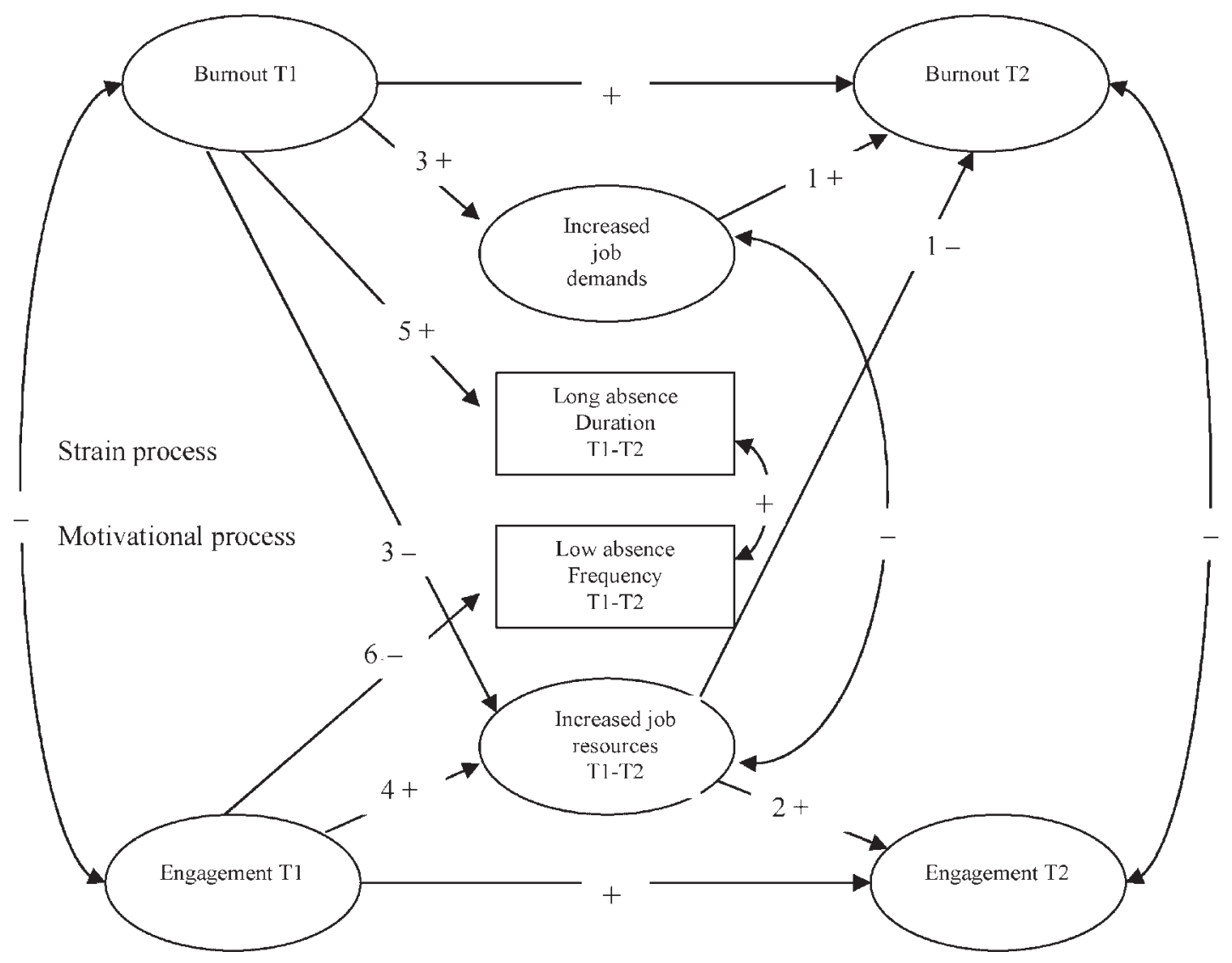

Figure 1. The research model

Note: The numbers refer to the hypotheses and the signs to the direction of the relationship (see text). 


\title{
Organizational Context
}

\begin{abstract}
Telecom Company
The company offers telecommunications services to both private consumers and business customers in The Netherlands. The core activities are telephony plus data services through the fixed network, and mobile telecommunications services. In 1989, a process of gradual privatization started that was completed in 2006. The company was privatized and because of the liberalization of the market, it was increasingly important for the company to reduce its prices, to accommodate to customer demands, and to improve its efficiency. As a consequence, since its privatization the company has gone through many reorganizations that resulted in massive redundancies. Although this was a time of a fairly strong economy with low unemployment rates and good job opportunities in the Dutch labor market, for the company it was the most difficult period in its long history. Namely, the company reached an all time high debt by buying UMTS licenses. This urged the company for further far-reaching measures such as reassessing alliances, accelerating restructuring processes, and further reducing its workforce.
\end{abstract}

\section{Telecom Industry}

The liberalization of the telecommunications sector is profoundly changing the content industry, as new ways of delivering content will be developed. Nowadays, content developers have a direct opportunity - through the Internet - to deliver their content to customers. This means that certain distribution channels cease to exist and new ones are created. Current markets for electronic information and communication services are still separated because of the required transport networks. With the emergence of new transparent digital platforms for the transmission of electronic information and communication, a single market for electronic data transport will develop independent of the type of application. However, this single transmission market will consist of many highly differentiated market segments in terms of supplied service management and applications. It is obvious that this market leads both to threats and opportunities for sound and effective market development in the telecom industry.

\section{Telecom Managers}

Study participants were managers and executives, most of whom had long tenures with the company (see sample). The telecom managers had to effectively manage-in addition to their daily work - redundancy programs, thereby mitigating adverse effects. Moreover, they had to coach the survivors and thus to deal with fairness issues that are related to redundancies. These managerial tasks call for social leadership, but most managers have a technical background and have been promoted in managerial jobs because they performed well in their previous, technical specialist job.

\section{Method}

\section{Sample}

A two-wave longitudinal study with a 1-year time interval took place among managers and executives of a Dutch telecom company that offers telecommunication services to both private consumers and 
business customers in The Netherlands (see box organizational context). At Time 1 (T1) all 420 middle managers and executives of the company were invited by the company's occupational health and safety service to participate in the study that was part of a recurring employee health and well-being survey (response rate $87 \% ; N=364$ ). One year later, at Time $2(\mathrm{~T} 2), 338$ managers and executives were invited to participate again in a similar health and well-being survey (response rate $62 \% ; N=210$ ). A 1 year follow-up was chosen because burnout (Schaufeli \& Enzmann, 1998) as well as work engagement (Schaufeli \& Salanova, 2007b) are defined as rather persistent psychological states that do not change very much in the short run. Due to turnover, death and pensioning, 26 respondents dropped out at T2. The panel group that completed both questionnaires and that is used in the present study consists of 201 employees. The T1 and T2 data of 9 respondents could not be linked for technical reasons, so that finally $48 \%$ of the initial sample was included in the panel.

The majority of the sample is male (89\%), 54\% holds at least a college degree, $35 \%$ completed a vocational training program, and $8 \%$ visited high school only. The mean age of the sample is 44.3 years $(\mathrm{SD}=7.6)$, and the managers work on average only 2 years $(\mathrm{SD}=2.5)$ in their current jobs but are on average 19.9 years employed at the company $(\mathrm{SD}=10.4)$. Thus, we deal with a typical managerial sample consisting of predominantly highly educated, experienced, middle-aged, and married men, who work in a turbulent organizational environment.

Selective dropout was only observed for age: compared to those who dropped out $(N=164)$, those who also participated at T2 $(N=201)$ were slightly older $(M=44.3$ versus $M=41.0 ; t(349)=3.96$; $p<.001)$. No selective dropout was found for gender $\left(\chi^{2}(1)=.01\right.$, n.s. $)$ or level of education $\left(\chi^{2}(7)=5.00\right.$, n.s.). Moreover, multivariate analysis of variance revealed that the mean scores on all study variables (i.e., demands, resources, burnout and engagement) of the dropouts did not differ from those who remained in the study, multivariate $F(12,319)=1.15$, n.s. It can therefore be concluded that selective drop-out is not a serious problem in the present study.

\section{Procedure}

At $\mathrm{T} 1$ and at the T2 follow-up 1 year later, the participants received a similar paper-and-pencil questionnaire with an accompanying letter that explained the purpose of the study, emphasized voluntary participation, and guaranteed confidentiality. Participants were asked to fill out the questionnaire and put it back into an envelope that was collected by members of the occupational health service of the company. Sickness absence data were collected by the company's occupational health service and linked to the questionnaire data, using a unique personnel code. Employees signed an informed consent before participating in the study.

\section{Instruments}

\section{Job demands}

Work overload ( 5 items; $\alpha_{\mathrm{T} 1}=.73 ; \alpha_{\mathrm{T} 2}=.78$ ) and emotional demands ( 3 items; $\alpha_{\mathrm{T} 1}=.79 ; \alpha_{\mathrm{T} 2}=.77$ ), representing quantitative and qualitative job demands, respectively, were assessed with shortened scales (e.g., Bakker, Demerouti, De Boer, et al., 2003; Bakker, Demerouti, \& Schavfeli, 2003; Bakker, Demerouti, Taris, et al., 2003; Bakker et al., 2004) of the questionnaire on the experience and evaluation of work (QEEW), which is widely used by Dutch occupational health services and applied researchers (Van Veldhoven \& Meijman, 1994; Van Veldhoven, De Jonge, Broersen, Kompier, \& Meijman, 2002). Example items are: "Do you have to work very fast?" (work overload) and "Does your work put you in emotionally upsetting situations?" (emotional demands). The third job demand, 
work-home interference, was measured by a scale developed by Peeters, De Jonge, Janssen and Van der Linden (2004) (7-items; $\left.\alpha_{\mathrm{T} 1}=.85 ; \alpha_{\mathrm{T} 2}=.88\right)$ that assesses time- and behavior-based interference. An example item is: "How often does it occur that you have so much to do at work that you cannot fulfill duties at home?"

\section{Job resources}

Using shortened scales of the QEEW, four job resources were assessed: social support (3 items; $\alpha_{\mathrm{T} 1}=.87 ; \alpha_{\mathrm{T} 2}=.87$ ), autonomy ( 3 items; $\alpha_{\mathrm{T} 1}=.79 ; \alpha_{\mathrm{T} 2}=.90$ ), opportunities to learn and to develop (4 items; $\left.\alpha_{\mathrm{T} 1}=.84 ; \alpha_{\mathrm{T} 2}=.84\right)$, and performance feedback ( 3 items; $\alpha_{\mathrm{T} 1}=.80 ; \alpha_{\mathrm{T} 2}=.82$ ). Example items are: "If necessary, can you ask your colleagues for help?" (social support); "Do you have freedom in carrying out your work activities?" (autonomy); "Do you learn new things in your work?" (opportunities to learn and to develop); "Does your work provide you with direct feedback on how well you are doing your work?" (feedback). All demands and resources items were scored on a 5point rating scale ranging from 1 ("never") to 5 ("always").

Burnout was assessed with two scales of the Dutch version (Schaufeli \& Van Dierendonck, 2000) of the Maslach burnout inventory - general survey (MBI-GS; Schaufeli, Maslach, Leiter, \& Jackson, 1996): Exhaustion (5 items) and Cynicism (4 items). Example items are: "I feel emotionally drained from my work" (exhaustion) and "I have become more cynical about whether my work contributes anything" (cynicism). All items were scored on a seven-point scale ranging from 0 ("never") to 6 ("always"). The MBI-GS has been successfully validated psychometrically in The Netherlands and elsewhere (e.g., Bakker, Demerouti, \& Schaufeli, 2002; Schutte, Toppinen, Kalimo, \& Schaufeli, 2000).

Work engagement was assessed with two scales of the Utrecht work engagement scale (UWES; Schaufeli, Salanova, González-Romá, \& Bakker, 2002): Vigor (6 items) and Dedication (5 items). Example items are: "At my job, I feel strong and vigorous" (vigor), and "I am enthusiastic about my job" (dedication). The engagement items are similarly scored as those of the MBI-GS. The UWES has been successfully psychometrically validated in The Netherlands and elsewhere (e.g., Schaufeli \& Bakker, 2004b; Storm \& Rothmann, 2003). The internal consistencies of the burnout and engagement scales can be found in Table 1 .

Sickness absence data was taken from the sickness absence records of the employees filed in the database of the company's occupational health service. Data on sick leave gathered from company records are clearly preferable as an outcome measure above sick leave data obtained from questionnaires or interviews (Van Poppel, De Vet, Smid, Koes, \& Bouter, 2002). As is usual in sickness absence research, a 1-year time interval was chosen in order to cancel out seasonal fluctuations in company's registered sickness absence (Steel, 2003). In addition, during the first year sickness absence is fully compensated in The Netherlands, after 1 year sick managers are considered work incapacitated and another social security regime applies. All spells of absence for medical reasons were centrally reported and registered by the executive manager. Absence spells longer than 2 weeks were verified by a company doctor by inviting the employee on sick leave so that the validity of the absence data is assumed to be high. Two sickness absence measures are used: absence frequency (i.e., the number of sick-leave spells between $\mathrm{T} 1$ and $\mathrm{T} 2$ ) and absence duration (i.e., the number of sick-leave days between $\mathrm{T} 1$ and $\mathrm{T} 2)$. The mean absence frequency was $.52(\mathrm{SD}=.83)$, and the mean absence duration was 9.9 days $(\mathrm{SD}=36.11)$. Since absence frequency and absence duration had considerable skewness $(1.72$ and 5.47, respectively) and kurtosis (3.18 and 14.43, respectively) a $\log 10$ transformation was performed in order to approach a normal distribution (Aiken \& West, 1991). After this transformation the indices for skewness and kurtosis were either within or below the ranges that are summarized by Steel (2003) and based on three sickness absence studies with 1-year time intervals. 


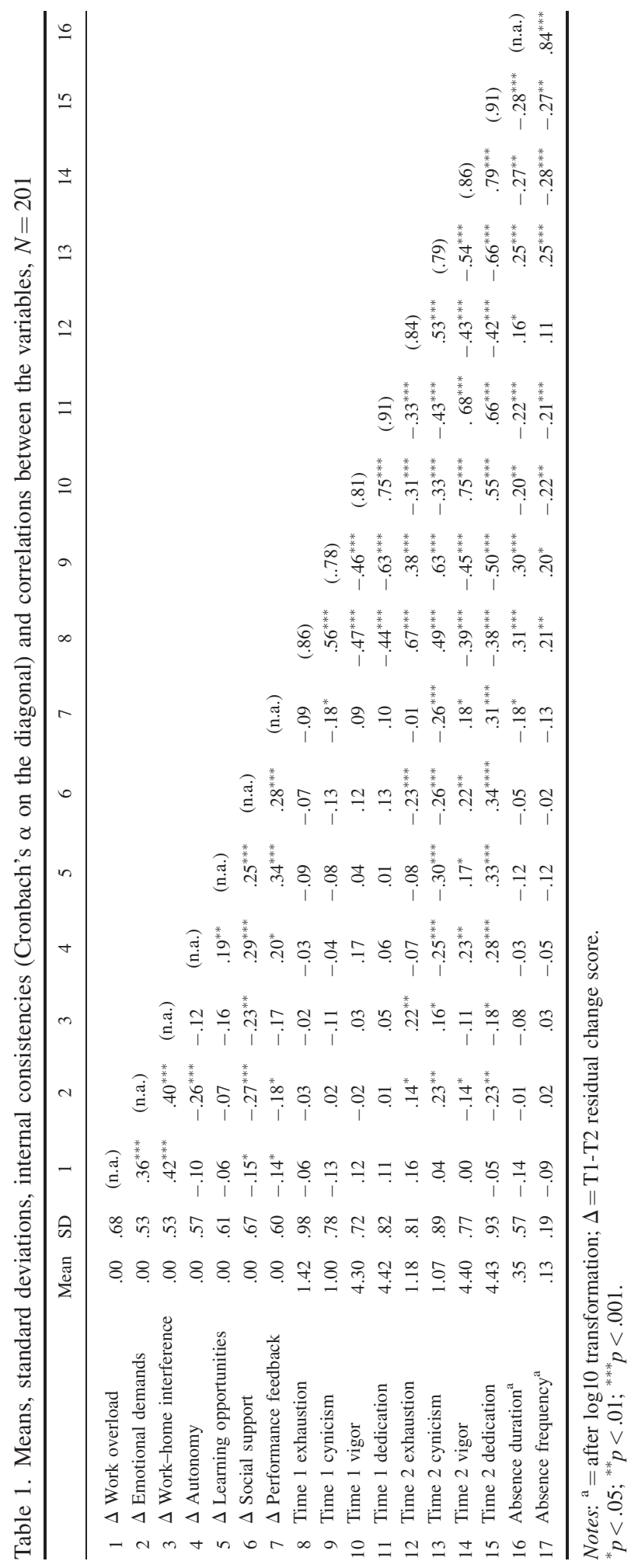


Analyses

Structural equation modeling methods as implemented by AMOS 5 (Arbuckle, 2003) were used to test the fit of the research model. Maximum likelihood estimation methods were used and the input for the analysis was the covariance matrix of the items. The goodness-of-fit of the model was evaluated using four absolute fit indices (cf. Jöreskog \& Sörbom, 1986): $\chi^{2}$ goodness-of-fit statistic, Goodness-of-fit index (GFI), Adjusted goodness-of-fit index (AGFI), and Root mean square error of approximation (RMSEA). Because $\chi^{2}$ is sensitive to sample size, meaning that the probability of rejecting a hypothesized model increases with sample size, two relative goodness-of-fit indices were calculated (Hu \& Bentler, 1999): Non-normed fit index (NNFI) and Comparative fit index (CFI). For these two fitindices, as a rule of thumb, values greater than .95 are considered as indicating a good fit, whereas values smaller than .06 for RMSEA are indicating an acceptable fit.

T1-T2 changes in demands and resources were measured as residual scores that were then included in the structural equation model (cf. Hobfoll, Johnson, Ennis, \& Jackson, 2003). Following the recommendations of Smith and Beaton (2008), these change scores were obtained by regressing T2 scores of the demands and resources on the corresponding $\mathrm{T} 1$ scores. The differences between the predicted and the observed scores of $\mathrm{T} 2$ demands and resources are the standardized residual scores that we used in the analyses. Positive residual scores indicate an increase and negative scores a decrease in demands or resources. Seven regression analyses were performed separately using the three demands and the four resources as dependent variables. This method of using residual scores as indicators of change has the advantage of not inflating error that might occur with the use of difference scores (Cronbach \& Furby, 1970). As recommended by Pitts, West, and Tein (1996), the corresponding measurement errors of the burnout and engagement indicators of T1 and T2 were allowed to covary over time; i.e., the error of $\mathrm{T} 1$ exhaustion with that of $\mathrm{T} 2$ exhaustion, and so on. The covariation of corresponding measurement errors across time accounts for the systematic (method) variance associated with each specific indicator.

\section{Results}

\section{Descriptive statistics}

Means, standard deviations, internal consistencies (Cronbach's $\alpha$ ) and correlations of all study variables are presented in Table $1 .{ }^{1}$ Note that, by definition, the mean values of the standardized residual scores are zero. As can be seen from Table 1, the internal consistencies of all scales meet the criterion of .70, a value that is used as a rule of thumb for sufficient reliability (Nunnally \& Bernstein, 1994).

\section{Test of measurement models}

Before testing the structural model that is displayed in Figure 1, three so-called measurement models that define relations between the observed and the unobserved or latent variables were fitted to the data. This first step is necessary to ensure that the latent variables are adequately representing the observed

\footnotetext{
${ }^{1}$ The full correlation matrix that also includes $\mathrm{T} 1$ and $\mathrm{T} 2$ demands and resources is available from the first author upon request.
} 
Table 2. Fit indices of measurement and structural models $(N=201)$

\begin{tabular}{lcccccccc}
\hline Model & $\chi^{2}$ & $\underline{\mathrm{df}}$ & GFI & AGFI & RMSEA & 90\% CI & NNFI & CFI \\
\hline Demands-resources (measurement models) & & & & & & \\
One-factor model at T1 & 511.88 & 343 & .85 & .82 & .05 & $.040-.058$ & .93 & .93 \\
One-factor model at T2 & 592.31 & 343 & .82 & .79 & .06 & $.052-.068$ & .90 & .91 \\
Two-factor model at T1 & 426.13 & 342 & .87 & .85 & .04 & $.023-.045$ & .96 & .97 \\
Two-factor model at T2 & 539.34 & 342 & .84 & .81 & .05 & $.054-.062$ & .92 & .93 \\
Null model at T1 & 2860.27 & 378 & .33 & .27 & .18 & $.175-.187$ & - & - \\
Null model at T2 & 3036.77 & 378 & .32 & .27 & .18 & $.181-.194$ & - & - \\
Research model $_{\text {Measurement model }}$ & 127.57 & 89 & .93 & .88 & .05 & $.037-.065$ & .96 & .98 \\
Hypothesized model $_{\text {Final model }}$ & 163.29 & 103 & .91 & .87 & .05 & $.036-.068$ & .95 & .96 \\
Null model $^{3}$ & 156.10 & 107 & .91 & .87 & .05 & $.039-.069$ & .95 & .96 \\
\hline
\end{tabular}

Notes:

${ }^{1}$ Includes all demands and resources at T1 without specifying any relationships among them.

${ }^{2}$ Includes all demands and resources at T2 without specifying any relationships among them.

${ }^{3}$ Includes all variables of the research model without specifying any relationships among them.

variables. The first measurement model that was tested includes all items of the scales that assess job demands and job resources at $\mathrm{T} 1$ and at $\mathrm{T} 2$. The question to be answered is whether the second-order two-factor structure with job demands (including work overload, emotional demands, and work-home interference) and job resources (including social support, autonomy, opportunities to learn and to develop, and performance feedback) fits to the data at both occasions. For that reason, this two-factor structure is compared with the one-factor model that assumes that all demands and all resources load on one general factor, representing job characteristics. As can be seen from Table 2, the hypothesized twofactor model fits well to the data of T1 and T2 with RMSA, NNFI, and CFI satisfying their respective criteria. All indicators load significantly on the latent variables, with coefficients ranging from .58 to .86 at T1 and from .48 to .88 at T2 (all $p$ 's $<.001$ ). Moreover, the fit of the two-factor second-order model is significantly better than that of the one-factor model that assumes that all demands and all resources load on one job characteristics factor (T1: $\Delta \chi^{2}=85.75, \mathrm{df}=2 ; p<.001 ; \mathrm{T} 2: \Delta \chi^{2}=52,97$, $\mathrm{df}=2 ; p<.001)$. Hence, it is concluded that two latent second-order factors-job demands and job resources - adequately represent the observed data.

The second measurement model was tested to the data in order to check whether or not the factor loadings of the scales were invariant across time. Such measurement invariance of scales is a prerequisite for valid time comparisons in longitudinal research. Each scale assessing job demands, job resources, burnout and work engagement was tested separately. ${ }^{2}$ A freely estimated model was compared with a model in which factor loadings at T1 and T2 were constrained to be equal. A $\chi^{2}$ difference test between both models did not produce any significant results (all $p$ 's $<.05$ ) so that it can be assumed that the factor loadings of all scales are invariant across time.

The third measurement model includes all six latent variables and two manifest sickness absence variables of the research model that are displayed in Figure 1. T1-T2 changes in work overload, emotional demands, and work-home interference were used as indicators of a latent variable representing changes in job demands ( $\Delta$ demands), whereas T1-T2 changes in autonomy, opportunities for leaning, feedback, and social support were used as indicators of a latent variable representing changes in job resource ( $\Delta$ resources). Furthermore, exhaustion and cynicism, and vigor and dedication

\footnotetext{
${ }^{2}$ Not included in Table 2. Results are available from the first author upon request.
} 
formed the $\mathrm{T} 1$ and $\mathrm{T} 2$ indicators of the latent burnout and work engagement factors, respectively. Finally, the observed $\log 10$ transformed absence duration and absence frequency between $\mathrm{T} 1$ and $\mathrm{T} 2$ were included in the measurement model. The measurement model assumes that all eight variables are distinct, yet correlated. As can be seen from Table 2, SEM-analyses revealed that this measurement model fit the data well with RMSEA, NNFI, and CFI meeting their respective criteria. Moreover, all indicators load significantly on the intended variables, with coefficients ranging from .45 to .89 (all $p$ 's $<.001)$. Hence, it is concluded that the six latent and two manifest variables in the model adequately represent the observed variables.

\section{Test of hypothesized structural equation model}

Next, the hypothesized structural model as depicted in Figure 1 was tested using SEM. Since no significant correlations were observed between age and any of the study variables $(.01<r<.11)$ there was no need to control for age. As can be seen from Table 2, the fit of the hypothesized model is good with RMSEA $<.06$ and both NNFI and CFI $\geq .95$.

However, inspection of the path-coefficients revealed that two path-coefficients were nonsignificant: the path from $\mathrm{T} 1$ burnout to $\Delta$ demands $(\beta=.14, p=.12)$, and the path from $\mathrm{T} 1$ burnout to $\Delta$ resources $(\beta=-.16, p=.09)$. In addition, the correlations of the T1 and T2 error terms of cynicism and dedication were not significant (.26 and .24 , respectively). After removing both non-significant paths and both non-significant error correlations, the fit of the hypothesized model improved slightly $\left(\Delta \chi^{2}=7.19, \mathrm{df}=2 ; p<.05\right)$. The resulting final model is depicted in Figure 2 . For reasons of parsimony, the observed variables are not displayed, but they all load significantly on their respective latent variables with coefficients ranging from .45 to .94 (all $p$ 's $<.001$ ). As can be seen from Figure 2, $81 \%$ of the variance in both T2 burnout and T2 engagement is explained by the model.

Hence, Hypothesis 1 is supported. This hypothesis stated that, after controlling for T1 burnout, T2 burnout is predicted by increasing demands and decreasing resources between T1 and T2. The effects of job demands and resources are about similar in size $(\beta=.23$ and $\beta=-.27$, respectively; see Figure 2). Thus the greater the increase in job demands and the decrease in job resources during the previous your the more burned-out managers feel, irrespective of their baseline level of burnout. Likewise Hypothesis 2 is supported that stated that, after controlling for T1 engagement, T2 engagement is predicted by an increase in resources between $\mathrm{T} 1$ and $\mathrm{T} 2(\beta=.45)$. In order to assess the uniqueness of the relationship between $\Delta$ resources and T2 engagement, an alternative model was tested that included the path running from $\Delta$ demands to T2 engagement. It appeared that this path was non-significant $(\beta=-.10$, n.s.), thus confirming the unique relationship of $\Delta$ resources and T2 engagement. Hence the greater the increase in job resources (but not in job demands) the previous year the more engaged managers feel, irrespective of their baseline level of engagement.

Hypotheses 3 stating that $\mathrm{T} 1$ burnout predicts $\mathrm{T} 1-\mathrm{T} 2$ absence duration is supported, as well as Hypothesis 4 that asserts that $\mathrm{T} 1$ engagement predicts $\mathrm{T} 1-\mathrm{T} 2$ absence frequency. As can be seen from Figure $2,3 \%$ of the variance in absence frequency and $7 \%$ in absence duration is explained by the model. In order to evaluate the uniqueness of T1 burnout and T1 engagement for absence duration and absence frequency, respectively, an alternative model was tested with additional paths running T1 burnout to absence frequency and from T1 engagement to absence duration. As expected, both paths were non-significant ( $\beta=-.14$, n.s. and $\beta=-.02$, n.s., respectively). Hence, it is concluded that the effects of T1 burnout and T1 engagement on T1-T2 absence duration and T1-T2 absence frequency, respectively, are unique. This means that, compared to managers with low levels of burnout, managers with high levels of burnout are likely to be longer (but not more frequently) on sick-leave during the 
following year. Contrarily, compared to managers with low levels of engagement managers with high levels of engagement are likely to be less often (nut not shorter) on sick-leave during the following year.

Hypothesis 5 about the existence of a loss cycle regarding burnout is not supported because the path from T1 burnout to $\Delta$ demands appeared to be non-significant. On the other hand, Hypothesis 6 is supported that assumes that $\mathrm{T} 1$ work engagement leads to an increase in job resources between $\mathrm{T} 1$ and $\mathrm{T} 2$, which, in its turn, fosters T2 engagement. In order to test the mediating effect of $\Delta$ resources, we fitted an alternative model to the data in which the paths running from T1 engagement to $\Delta$ resources, and from $\Delta$ resources to T2 engagement were eliminated (thus assuming no mediation). Compared to the final model, the fit of this alternative model to the data deteriorated significantly $\left(\Delta \chi^{2}=58.26\right.$, $\mathrm{df}=2 ; p<.001$ ). Instead of explaining $81 \%$ of the variance (see Table 2), the alternative model explains only $61 \%$ of the variance of $\mathrm{T} 2$ engagement. In addition, the results of a Sobel-test confirm mediation by $\Delta$ resources $(z=2.18 ; p<.05)$ of the T1-T2 engagement relationship. Thus, the increase of resources between $\mathrm{T} 1$ and $\mathrm{T} 2$ plays a partial mediating role, adding a substantial proportion of explained variance in T2 work engagement over and above T1 work engagement. Hence, the notion of a gain cycle that involves work engagement and job resources is corroborated by our findings. This means that managers who initially feel engaged are likely to perceive an increase in job resources in the following year, which, in its turn, makes them feel more engaged 1 year later.

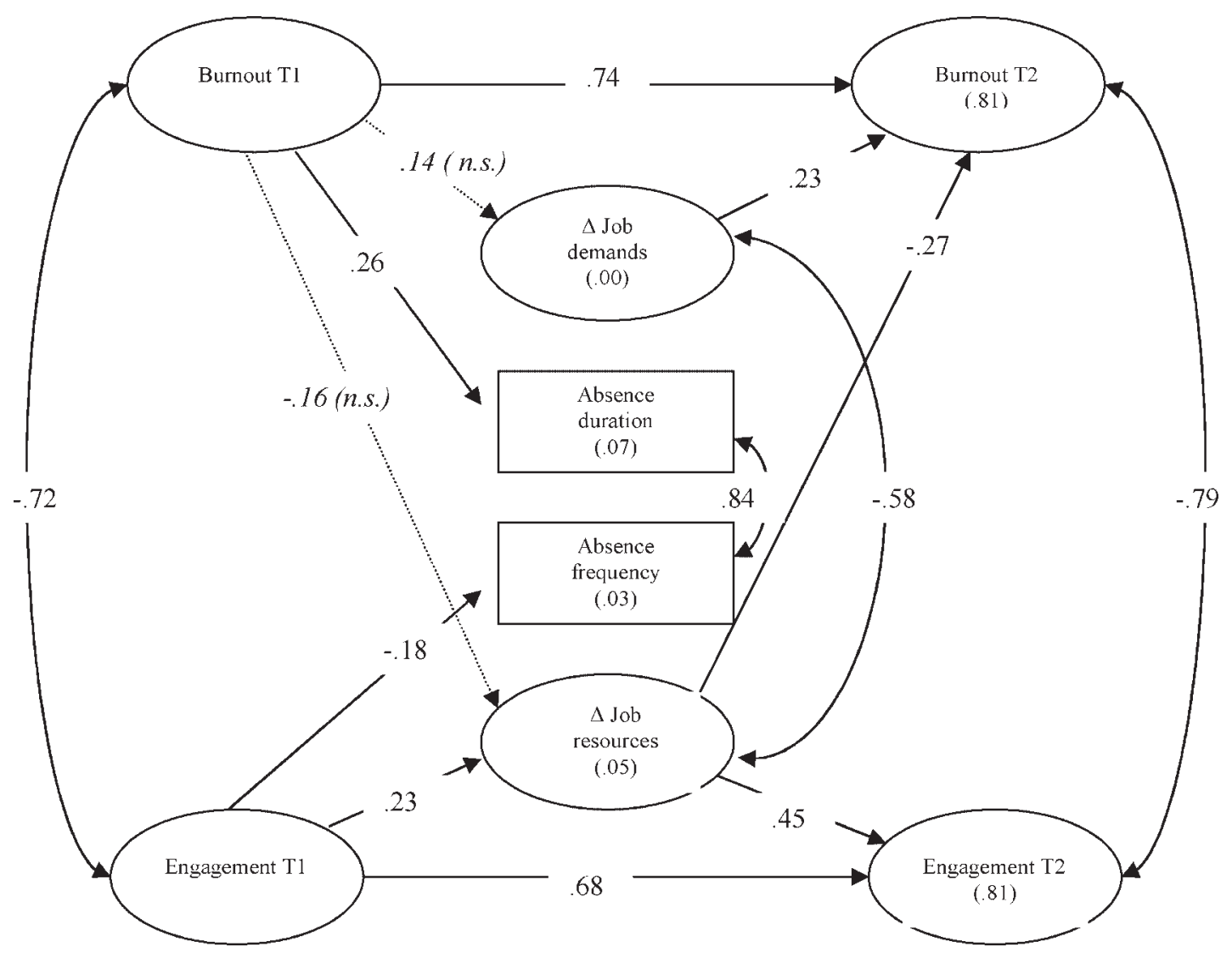

Figure 2. The final model $(N=201)$

Note: Dotted lines represent non-significant paths in the hypothesized model. Proportions explained variance between brackets. 


\section{Discussion}

The aim of the current study among managers of a telecom company was threefold: (1) to provide longitudinal evidence for the Job Demands-Resources (JD-R) model; (2) to investigate the dynamic nature of the model in terms of loss and gain cycles; and (3) to integrate prospective company registered sickness absenteeism into the JD-R model.

\section{Longitudinal evidence for the job demands-resources model}

Our results indicate that changes in job demands and job resources predict future burnout and work engagement. More specifically, when job demands (i.e., work overload, emotional demands, and workhome interference) increase, and job resources (i.e., job control, feedback, social support, and opportunities for learning) decrease, future burnout scores increase, also after controlling for initial burnout (Hypothesis 1). This agrees with many cross-sectional and (some) longitudinal studies on the antecedents of burnout (for reviews, see Halbesleben \& Buckley, 2004; Schaufeli \& Enzmann, 1998). These studies showed that-particularly exhaustion and cynicism-are positively related to job demands such as work overload, emotional demands, and work-home interference, and negatively related to job resources, such as autonomy, performance feedback, social support and opportunities for professional development. In a similar vein, our study established a longitudinal link between increasing demands and the development of burnout, thereby corroborating the strain process as assumed by the JD-R model.

Simultaneously, when job resources increase, work engagement tends to increase as well, also after controlling for initial engagement (Hypothesis 2). Furthermore and as expected, changes in demands do not affect future levels of work engagement. Hence, supplementing previous cross-sectional studies using the JD-R model (e.g., Hakanen et al., 2006; Llorens et al., 2006; Schaufeli \& Bakker, 2004a), the current study confirms that (changes in) demands and resources predict future burnout and work engagement. Our findings also agree with a number of studies that found positive associations between work engagement and job resources, including social support from co-workers and superiors, performance feedback, coaching, autonomy, task variety, and training facilities (for an overview, see Schaufeli \& Salanova, 2007b). Hence, overall our results support the existence of a motivational process as proposed by the JD-R model.

\section{Sickness absenteeism and the job demands-resources model}

As far as sickness absence is concerned, our findings indicate that initial burnout predicts future absence duration, but not absence frequency (Hypothesis 3), whereas initial levels of work engagement predict future absence frequency, but not absence duration (Hypothesis 4). Thus, as expected, burnout is associated with "involuntary" absenteeism and leads to longer sickness absence, whereas work engagement is associated with "voluntary" absenteeism and leads to less frequent absences. The former agrees with several studies that indicate that burnout is positively associated with sickness absenteeism (e.g., Bakker, Demerouti, De Boer, et al., 2003; Firth \& Britton, 1989; Lawson \& O'Brien, 1994; Price \& Spence, 1994; Saxton, Phillips, \& Blakeney, 1991). Recently, a study using a large representative Finnish sample found that those with severe burnout had 52 excess sickness absence days during the 2 year study period, as compared to those with low burnout scores (Ahola, et al., 2008). Except for the study of Bakker, Demerouti, De Boer, et al. (2003a), no differentiation is made between 
absence duration and absence frequency. Our results confirm those obtained in this Finnish study: high job demands (and not lacking job resources) were related to absence duration, whereas lacking job resources (and not high job demands) were related to absence frequency. It should be noted that the variance in absenteeism that is explained by burnout in the above-mentioned studies ranges between $2-$ $4 \%$, which is slightly lower than is explained in the current study (3-7\%).

As our study illustrates, distinguishing between both absence measures is important because both outcomes seem to refer to different processes: involuntary absenteeism being the result of job strain (e.g., burnout), and voluntary absenteeism being the results of lacking motivation (e.g., engagement), respectively (cf. Chadwick-Jones et al., 1982). In line with the predictions of the JD-R model (see Figure 1), absence duration is particularly linked with the strain process, whereas absence frequency is particularly linked with the motivational process. This is particularly remarkable given the fact that the correlation between absence frequency and duration is quite substantial. Usually, correlations between absence frequency and duration range between -.05 and .60 (Farrell \& Stam, 1988), as was the case in our study before the $\log 10$ transformation $(r=.38)$. Note that our findings regarding sickness absence underscore the existence of a strain and a motivational process.

\section{Loss and gain cycles}

Our findings go beyond the mere longitudinal validation of the JD-R model by illustration of its dynamic nature, particularly as far as the motivational process is concerned. In contrast to the strain process that did not seem to initiate a loss cycle of increasing demands and decreasing resources (Hypothesis 5), indications were found for the existence of a gain cycle of resources (Hypothesis 6). That is, high initial levels of work engagement predicted an increase of job resources over the next year, which, in its turn, resulted in more engagement at the end of that year. The latter agrees with CORtheory that predicts that resource gain will lead to greater well-being (Hobfoll \& Shirom, 2002; Hobfoll et al., 2003). However, the current study goes one step further by showing that well-being (engagement) leads to future resource gain, which suggests a gain cycle in which resources and engagement reinforce each other reciprocally. This is in line with the results of a recent experiment among university students that showed that task resources (i.e., time and method control) predicted later engagement and that engagement predicted later task resources - through efficacy beliefs (Llorens et al., 2007).

Such reciprocal relationships are not only consistent with the notion of gain cycles, as proposed by COR-theory (Hobfoll \& Shirom, 2002), but also with the recently formulated broaden-and-build theory (Fredrickson, 2001, 2003) and with the related socially embedded model of thriving at work (Spreitzer, Sutcliffe, Dutton, Sonnenschein \& Grant, 2005). Research with the broaden-and-build theory showed that momentary experiences of positive emotions can build enduring personal resources and trigger upward spirals toward emotional well-being (Fredrickson \& Joiner, 2002). Applying the work of Fredrickson $(2001,2003)$ to the work situation, Spreitzer et al. (2005) propose a theoretical model that includes a type of positive spiral between the resources created in the doing of work and "thriving", a concept that overlaps with engagement and includes vitality and a sense of learning. This spiral is fueled by "agentic work behaviors", such as task focus, exploration, and heedful relating. Such notions of upward spirals are compatible with our results that suggest that engagement builds job resourcespresumably by broadening the employee's thought-action repertoire or through agentic work behaviors - and as a result employees feel better-i.e., more engaged.

Finally, our results on the gain cycle also seem to agree with observations from an in-depth interview study in which engaged employees indicated that they generated their own positive feedback, for instance, by being extra friendly and helpful to customers so that they are more likely to express their gratitude (Schaufeli, Taris, Le Blanc, Peeters, Bakker, \& De Jonge, 2001). However, it should be 
pointed out that an alternative explanation cannot be ruled out: rather than actually building resources, engaged managers could also have changed their perception of resources (i.e., being more aware of their existence). Evidently, only the inclusion of objective indicators of job resources (e.g., number of social interactions, pay increase) may resolve this issue.

In contrast, no support was found for the existence of a loss cycle, where high job demands and a loss of resources would result in burnout symptoms, which, in their turn, would lead to higher job demands and fewer job resources. This is remarkable, not only because bad events generally have greater impact than good events (cf. Baumeister, Bratslansky, Finkenauer, \& Vohs, 2001), but also because CORtheory assumes that people are primarily motivated to protect themselves from resource loss, which makes loss more salient than gain (Hobfoll \& Shirom, 2002). Seen from this perspective, it would have been more likely to find empirical support for the existence of a loss cycle rather than a gain cycle. Although resource loss between $\mathrm{T} 1$ and T2 predicted T2 burnout (Hypothesis 1), T1 burnout did not predict resource loss (Hypothesis 5). It should be noted that observing reversed causation is the exception rather than the rule in longitudinal research, as is illustrated by the review of Zapf, Dormann, and Frese (1996). They found reversed causal effects only in six out of sixteen studies, so roughly in one-third of the cases.

Nevertheless, we can speculate why in the current study "normal" causation is observed, but not reciprocal causation. One possible explanation is that employees with high (clinical) levels of burnout withdraw from the organization (absenteeism, personnel turnover) before they seriously impact on job demands (e.g., make mistakes and therefore increase their own demands) and job resources (e.g., no longer receive support from colleagues or positive feedback because of their cynicism). Thus, the "healthy worker effect" may prevent (relatively low levels of) "burnout" to have an impact on the work environment. Furthermore, a floor effect of burnout might exist because in the current sample levels of exhaustion $(t(389)=2.65, p<.001)$ and cynicism $(t(389)=4.10, p<001)$ are significantly lower compared to a reference group of managers from the test manual (Schaufeli \& Van Dierendonck, 2000). However, on the other hand, a significant effect of burnout on absence duration was found, which seems to contradict this interpretation. Finally, another possible methodological explanation is the lack of statistical power because only about 200 employees were included; after all, the pathcoefficients were in the expected direction and their strength just lacked significance. Taken together it seems that rather than continuing with their work and experiencing increased job demands, managers with elevated burnout scores at $\mathrm{T} 1$ report themselves sick.

\section{Study limitations and suggestions for future research}

Recently, Schaufeli and Bakker (2004a) proposed three recommendations for future research on the JD-R model that were all followed in the present study: (1) a longitudinal design should be used, (2) objective outcomes such as sickness absenteeism should be included, and (3) job resources should be included that are more distal from job demands, such as learning opportunities. Nevertheless, some more work needs to be done. For instance, in order to study lagged mediation effects (e.g., high job demands $\rightarrow$ burnout $\rightarrow$ absence duration) a three-wave longitudinal design is necessary (Cole \& Maxwell, 2003). Also, the need remains to include other objective outcomes such as, for instance, objective performance (Harter, Schmidt, \& Hayed, 2002), and other distal resources, such as, for instance, career perspectives.

As in virtually all sickness absence studies absence frequency and absence duration were not normally distributed in our study, albeit that skewness and kurtosis of both absence indicators were within ranges found in other studies (Steel, 2003). As suggested by Steel and Rentsch (1995) considerable distributional smoothing may occur for absence measures when they are cumulated over 
lengthy periods. In their study, they varied the period of data cumulation over the range $2-70$ months and found that longer periods of data cumulation (i.e., 3 years or more) resulted in distributional smoothing, particularly for absence duration. Hence, future studies should consider using longer time intervals for collecting absence data.

A possible limitation of the current study is the low percentage of variance explained in absence frequency (3\%) and absence duration (7\%). However, this is in line with other studies, for instance on burnout and absenteeism (Schaufeli \& Enzmann, 1998; p. 91) and hardly surprising since work-related stress is but one of many variables accounting for employee absence behavior (Michie \& Williams, 2003). Non-work variables accounting for absenteeism include a wide range of factors, such as personal characteristics, sport injuries, smoking, alcohol consumption, psychological disorders, and physical pain (cf. Johns, 1997). This also applies for the employee's health status. For instance, it cannot be ruled out that such non-work variables, including employee health - might have influenced "involuntary" absenteeism. Hence, in order to explain more variance in absence behavior these factors should be included in future research as well.

In The Netherlands, sickness absence of employees is almost completely financially compensated during the first year, so that no loss of income is experienced by the managers on sick leave who participated in our study. It cannot be ruled out that in other countries, where sickness absenteeism leads to income loss, different results would be obtained, particularly for absence frequency because this is an indicator of employee motivation (Johns, 1997). For instance, in countries where financial losses occur, disengaged employees might be less inclined to be absent from work for short spells.

Finally, the specific sample under study - a relatively small group of managers from one specific large company-could be considered a weakness because its homogeneous nature limits the generalization of our findings to other occupational groups. However, managers are an important group to investigate because they pay a key role in organizations and it has been argued that healthy managers and executives make an important economic contribution to their organization (Quick \& Cooper, 2002). Nevertheless, despite the small sample size we observed significant relationships between the study variables. This is - most likely - due to the fact that we deliberately reduced the number of estimated parameters in the model, for instance by including residual scores. In future studies with larger samples more elaborated versions of the JD-R model could be tested, for instance including personal resources as well.

\section{Practical implications}

There is a growing recognition that the organization's financial health correlates with investments in employee well-being (Goetzel, Guindon, Turshen, \& Ozminskowski, 2001) so that there is an economic incentive for reducing burnout and building engagement. Our results indicate that changes in job demands predict future burnout and burnout predicts future absence duration. In addition, work engagement was found to predict future absence frequency. These findings illustrate the importance of our study for organizations. In order to be effective in reducing burnout - and thus absence durationtwo avenues may be followed. First, reducing exposure to job demands such as work overload, emotional demands, and work-home interference, and second, providing job resources such as job autonomy, learning opportunities, social support, and performance feedback (cf. Schaufeli \& Enzmann, 1988; pp. 143-183). Our results show that in order to increase engagement reducing the exposure to job demands is not the best option; instead, the motivating potential of job resources should be exploited. Resources are not only necessary to deal with job demands and to "get things done", but they also are important in their own right because they increase work engagement. In contrast, the lack of organizational resources has a detrimental effect not only on employee burnout (Lee \& Ashforth, 
1996), but also on employee motivation and performance (Wong, Hui, \& Law, 1998) since it precludes actual goal accomplishment, and undermines employees' learning opportunities (Kelly, 1992). In addition, providing job resources would set in motion a gain cycle that is not only likely to result in higher levels of engagement, but also to increase job resources and reduce absence frequency.

The so-called Vitamin Model of Warr (2007) provides a shortlist of nine types of job resources ("vitamins") that are related to employee health and well being: (1) opportunity for control; (2) opportunity for skill use; (3) externally generated goals; (4) variety; (5) environmental clarity; (6) availability of money; (7) physical security; (8) opportunity for interpersonal contact; and (9) valued social position. These nine categories that can be further broken down in sub-categories may be used to systematically assess the profile of resources in a particular job so that lacking resources can be tracked down and, if necessary, provided.

Another practical implication that follows from our study is that different strategies should be followed in order to reduce sickness duration or sickness frequency among employees. Our results confirm that the former- "involuntary" absence - is an indicator of job stress that is linked to the strain process, whereas the latter-low "voluntary" absence - is an indicator of employee motivation (cf. Chadwick-Jones et al., 1982). This means that: (1) when registering absenteeism organizations should differentiate between duration and frequency; (2) when targeting to reduce sickness duration levels, burnout (i.e., employee unwell-being) should be decreased, for instance by reducing job demands and increasing job resources; (3) when targeting to reduce sickness absence frequency, levels of engagement (i.e., employee well-being) should be promoted, for instance by providing additional job resources.

\section{Final note}

On balance, our results support the JD-R model and the notion of a strain process and a motivational process (see Figure 1). The JD-R model integrates the traditional "negative" view on employee wellbeing (burnout) with a "positive" view (engagement) and thus provides a more balanced approach of employee well-being. Therefore, the JD-R model may bridge the gap between occupational health management and human resources management that are traditionally concerned with job strain and motivation, respectively.

\section{Author biographies}

Wilmar B. Schaufeli is full professor of Work and Organizational Psychology at Utrecht University, The Netherlands. He received his Ph.D. cum laude in clinical psychology from the University of Groningen. His research area is occupational health psychology and includes job stress, burnout, absenteeism, work engagement, workaholism, and worksite health interventions. He published over three hundred articles and chapters, and authored or edited about a dozen books. For more details see: www.schaufeli.com.

Arnold B. Bakker is full professor of Work and Organizational Psychology at Erasmus University Rotterdam, The Netherlands. He received his Ph.D. in social psychology from the University of Groningen. His research interests include positive organizational psychology (e.g., flow and engagement at work, job performance), burnout, spillover and crossover of work-related emotions, and internet applications of organizational psychology. His research has been published in journals such as 
Journal of Applied Psychology, Journal of Vocational Behavior, Journal of Occupational Health Psychology, and Human Relations.

Willem van Rhenen is occupational physician and Chief Medical Officer of one of the largest Occupational Health Services in the Netherlands, offering services to 1.1 million employees. He received his Ph.D. in occupational medicine from the University of Amsterdam. His research is mainly focused on stress management in the workplace and more recently on work engagement.

\section{References}

Ahola, K., Kivimäki, M., Honkonen, T., Virtanen, M., Koskinen, S., Vahtera, J., et al. (2008). Occupational burnout and medically certified sickness absence: A population-based study of Finnish employees. Journal of Psychosomatic Research, 64, 185-193.

Aiken, L. S., \& West, S. G. (1991). Multiple regression: Testing and interpreting interactions. Newbury Park, CA: Sage.

Arbuckle, J. L. (2003). Amos 5.0 User's Guide. Chicago, IL: SPSS, Inc.

Bakker, A. B., \& Demerouti, E. (2007). The job demands-resources model: State of the art. Journal of Managerial Psychology, 22, 309-328.

Bakker, A. B., Demerouti, E., De Boer, E., \& Schaufeli, W. B. (2003). Job demands and job resources as predictors of absence duration and frequency. Journal of Vocational Behavior, 62, 341-356.

Bakker, A. B., Demerouti, E., \& Euwema, M. C. (2005). Job resources buffer the impact of job demands on burnout. Journal of Occupational Health Psychology, 10, 170-180.

Bakker, A. B., Demerouti, E., \& Schaufeli, W. B. (2002). Validation of the Maslach burnout inventory - general survey: An Internet study. Anxiety, Stress \& Coping, 15, 245-260.

Bakker, A. B., Demerouti, E., \& Schaufeli, W. B. (2003). Dual processes at work in a call centre: An application of the job demands-resources model. European Journal of Work and Organizational Psychology, 12, 393-417.

Bakker, A. B., Demerouti, E., Taris, T., Schaufeli, W. B., \& Schreurs, P. (2003). A multi-group analysis of the job demands-resources model in four home care organizations. International Journal of Stress Management, 10, $16-38$.

Bakker, A. B., Demerouti, E., \& Verbeke, W. (2004). Using the job demands-resources model to predict burnout and performance. Human Resource Management, 43, 83-104.

Bakker, A. B., \& Schaufeli, W. B. (2008). Positive organizational behavior: Engaged employees in flourishing organizations. Journal of Organizational Behavior, 29, 147-154.

Baumeister, R. F., Bratslansky, E., Finkenauer, C., \& Vohs, K. D. (2001). Bad is stronger than good. Review of General Psychology, 5, 23-370.

Burke, R. J. (1988). Sources of managerial stress and professional stress in large organizations. In C. L. Cooper, \& R. Payne (Eds.), Causes, coping and consequences of stress at work (pp. 77-114). Chichester: Wiley.

Chadwick-Jones, J. K., Nicholson, N., \& Brown, C. (1982). Social psychology of absenteeism. New York: Praeger.

Cole, A., \& Maxwell, S. E. (2003). Testing mediational models with longitudinal data: Questions and tips in the use of structural equation modeling. Journal of Abnormal Psychology, 112, 558-577.

Cronbach, L. J., \& Furby, J. (1970). How should we measure change—or should we? Psychological Bulletin, 74, 26-37.

Csikszentmihalyi, M. (1990). Flow: The psychology of optimal experience. New York: Harper.

Deci, W. L., \& Ryan, R. M. (2000). The "what" and "why" of goal pursuits: Human needs and the selfdetermination of behavior. Psychological Inquiry, 11, 319-338.

Dekkers-Sanchez, P. M., Hoving, J. L., Sluiter, J. K., \& Frings-Dresen, M. H. W. (2008). Factors associated with long-term sick leave in sick-listed employees: A systematic review. Occupational and Environmental Medicine, 65, 153-157.

De Lange, A. H., Taris, T. W., Kompier, M. A. J., Houtman, I. L. D., \& Bongers, P. M. (2004). The relationship between work characteristics and mental health: Examining normal, reversed and reciprocal relationships in a 4-wave study. Work \& Stress, 18, 149-166. 
Demerouti, E., Bakker, A. B., \& Bulters, A. J. (2004). The loss spiral of work pressure, work-home interference and exhaustion: Reciprocal relations in a three-wave study. Journal of Vocational Behavior, 64, 131-149.

Demerouti, E., Bakker, A. B., De Jonge, J., Janssen, P. P. M., \& Schaufeli, W. B. (2001). Burnout and engagement at work as a function of demands and control. Scandinavian Journal of Work, Environment \& Health, 27, 279286.

Demerouti, E., Bakker, A. B., Nachreiner, F., \& Schaufeli, W. B. (2001). The job demands-resources model of burnout. Journal of Applied Psychology, 86, 499-512.

Dwyer, D. J., \& Ganster, D. C. (1991). The effect of job demands and control on employee attendance and satisfaction. Journal of Applied Psychology, 86, 499-512.

Farrell, D., \& Stam, C. L. (1988). Meta-analysis of the correlates of employee absence. Human Relations, 41, 211227.

Firth, H., \& Britton, P. G. (1989). "Burnout", absence and turnover amongst British nursing staff. Journal of Occupational Psychology, 62, 55-59.

Fredrickson, B. L. (2001). The role of positive emotions in positive psychology: The broaden-and-build theory of positive emotions. American Psychologist, 56, 218-226.

Fredrickson, B. L., \& Joiner, T. (2002). Positive emotions trigger upward spirals toward emotional well-being. Psychological Science, 13, 172-175.

Fredrickson, B. L. (2003). Positive emotions and upward spirals in organizations. In K. S. Cameron, J. E. Dutton, \& R. E. Quinn (Eds.), Positive organizational scholarship: Foundations of a new discipline (pp. 163-175). San Francisco, CA: Berrett-Koehler.

Goetzel, R. Z., Guindon, A. M., Turshen, I. J., \& Ozminkowski, R. J. (2001). Health and productivity management: Establishing key performance measures, benchmarks, and best practices. Journal of Occupational and Environmental Medicine, 43, 10-17.

Goff, S. J., Mount, M. K., \& Jamison, R. L. (1990). Employer supported childcare, work/family conflict and absenteeism: A field study. Personnel Psychology, 43, 793-809.

González-Romá, V., Schaufeli, W. B., Bakker, A. B., \& Lloret, S. (2006). Burnout and engagement: Independent factors or opposite poles? Journal of Vocational Behavior, 68, 165-174.

Green, D. E., Walkey, F. H., \& Taylor, A. J. W. (1991). The three-factor structure of the Maslach burnout inventory. Journal of Science Behavior and Personality, 6, 453-472.

Hakanen, J. J., Bakker, A. B., \& Schaufeli, W. B. (2006). Burnout and work engagement among teachers. Journal of School Psychology, 43, 495-513.

Halbesleben, J. R. B., \& Buckley, M. R. (2004). Burnout in organizational life. Journal of Management, 30, 859879.

Harter, J. K., Schmidt, F. L., \& Hayes, T. L. (2002). Business-unit-level relationship between employee satisfaction, employee engagement, and business outcomes: A meta-analysis. Journal of Applied Psychology, 87, 268-279.

Hobfoll, S. E., \& Shirom, A. (2000). Conservation of resources theory: Applications to stress and management in the workplace. In R. T. Golembiewski (Ed.), Handbook of organization behavior (2nd ed., pp. 57-81). New York: Dekker.

Hobfoll, S. E., Johnson, R. J., Ennis, J. E., \& Jackson, A. P. (2003). Resource loss, resources gain and emotional outcomes among inner city women. Journal of Personality and Social Psychology, 84, 632-643.

Hockey, G. J. (1993). Cognitive-energetical control mechanisms in the management of work demands and psychological health. In A. D. Baddeley, \& L. Weiskrantz (Eds.), Attention, selection, awareness and control: A tribute to Donald Broadbent (pp. 328-345). Oxford: Oxford University Press.

Hockey, G. J. (1997). Compensatory control in the regulation of human performance under stress and high workload: A cognitive-energetical framework. Biological Psychology, 45, 73-93.

Hu, L. T., \& Bentler, P. M. (1999). Cutoff criteria for fit indices in covariance structure analyses: Conventional criteria versus new alternatives. Structural Equation Modeling, 6, 1-55.

Iverson, I. D., Olekalns, M., \& Erwin, P. J. (1998). Affectivity, organizational stressors, and absenteeism: A causal model of burnout and its consequences. Journal of Vocational Behavior, 52, 1-23.

Jones, F., \& Fletcher, B. C. (1996). Job control and health. In M. J. Schabracq, J. A. M. Winnubst, \& C. L. Cooper (Eds.), Handbook of work and health psychology (pp. 33-50). Chichester: Wiley.

Johns, G. (1997). Contemporary research on absence from work: Correlates, causes and consequences. International Review of Industrial and Organizational Psychology, 12, 115-173.

Jöreskog, K. G., \& Sörbom, D. (1986). LISREL user guide version VI (4th ed.). Mooresville, Ill: Scientific Software International. 
Karasek, R. A. (1979). Job demands, job decision latitude, and mental strain: Implications for job redesign. Administrative Science Quarterly, 24, 285-308.

Kelly, J. E. (1992). Does job re-design theory explain job re-design outcomes? Human Relations, 45, $753-774$.

Kohler, S. S., \& Mathieu, J. E. (1993). Individual characteristics, work perceptions, and affective reactions influences on differentiated absence criteria. Journal of Organizational Behavior, 14, 37-54.

Kristensen, T. S. (1991). Sickness absence and work strain among Danish slaughterhouse workers: An analysis of absence from work regarded as coping behaviour. Social Science \& Medicine, 32, 15-27.

Lawson, D. A., \& O’Brien, R. M. (1994). Behavioral and self-report measures of staff burnout in development disabilities. Journal of Organizational Behavior Management, 14, 37-54.

Lee, R. T., \& Ashforth, B. E. (1996). A meta-analytic examination of the correlates of thee three dimensions of job burnout. Journal of Applied Psychology, 81, 123-133.

Leiter, M. P. (1993). Burnout as developmental process: Consideration of models. In W. B. Schaufeli, C. Maslach, \& T. Marek (Eds.), Professional burnout: Recent developments in theory and research (pp. 237-250). Washington, DC: Taylor and Francis.

Lewig, K. A., \& Dollard, M. F. (2003). Emotional dissonance, emotional exhaustion and job satisfaction in call centre workers. European Journal of Work and Organizational Psychology, 12, 366-392.

Llorens, S., Bakker, A. B., Salanova, M., \& Schaufeli, W. B. (2006). Testing the robustness of the job demandsresources model. International Journal of Stress Management, 31, 378-391.

Llorens, S., Schaufeli, W. B., Bakker, A. B., \& Salanova, M. (2007). Does a positive gain spiral of resources, efficacy beliefs and engagement exist? Computers in Human Behavior, 23, 825-841.

Luthans, F. (2003). Positive organizational behavior (POB): Implications for leadership and HR development and motivation. In R. M. Steers, L. W. Porter, \& G. A. Bigley (Eds.), Motivation and leadership at work (pp. 178195). New York: McGraw-Hill.

Maslach, C., Schaufeli, W. B., \& Leiter, M. P. (2001). Job burnout. Annual Review of Psychology, 52, $397-422$.

Mathieu, J. E., \& Kohler, S. S. (1990). A test of the interactive effects of organizational commitment and job involvement on various types of absence. Journal of Vocational Behavior, 36, 33-44.

Mauno, S., Kinnunen, U., \& Ruokolainen, M. (2007). Job demands and resources as antecedents of work engagement: A longitudinal study. Journal of Vocational Behavior, 70, 149-171.

Meijman, T. F., \& Mulder, G. (1998). Psychological aspects of workload. In P. J. D. Drenth, \& H. Thierry (Eds.), Handbook of work and organizational psychology, Vol. 2: Work psychology (pp. 5-33). Hove: Psychology Press.

Michie, S., \& Williams, S. (2003). Reducing work related ill-health and sickness absence: A systematic literature review. Occupational and Environmental Medicine, 60, 3-9.

Neveu, J. P. (2007). Jailed resources: Conservation of resources theory as applied to burnout among prison guards. Journal of Organizational Behavior, 28, 21-42.

Nunnally, J. C., \& Bernstein, I. H. (1994). Psychometric theory (3rd ed.). New York: McGraw-Hill.

Parker, J. A., \& Kulik, J. A. (1995). Burnout, self- and supervisor-rated job performance, and absenteeism among nurses. Journal of Behavioral Medicine, 52, 581-599.

Peeters, M. C. W., De Jonge, J., Janssen, P. P. M., \& Van der Linden, S. (2004). Work-home interference, job stressors, and employee health in a longitudinal perspective. International Journal of Stress Management, 11, 305-322.

Pitts, S. C., West, S. G., \& Tein, J. Y. (1996). Longitudinal measurement models in evaluation research: Examining stability and change. Evaluation and Program Planning, 19, 333-350.

Price, L., \& Spence, S. H. (1994). Burnout symptoms amongst drug and alcohol service employees: Gender differences in the interaction between work and home stressors. Anxiety, Stress \& Coping, 7, 67-84.

Quick, J. D., \& Cooper, C. L. (2002). Executive health: building self-reliance for challenging times. In C. L. Cooper, \& I. T. Robinson (Eds.), International review of industrial and organizational psychology (Vol. 17, pp. 187-216).

Ryan, R. M., \& Frederick, C. M. (1997). On energy, personality, and health: Subjective vitality as a dynamic reflection of well-being. Journal of Personality, 65, 529-565.

Salanova, M., Llorens, S., Cifre, E., Martínez, I., \& Schaufeli, W. B. (2003). Perceived collective efficacy, subjective well-being and task performance among electronic work groups: An experimental study. Small Group Research, 34, 43-73.

Salanova, M., Bakker, A. B., \& Llorens, S. (2006). Flow at work: Evidence for an upward spiral of personal and organizational resources. Journal of Happiness Studies, 7, 1-22.

Sagie, A. (1998). Employee absenteeism, organizational commitment and job satisfaction: Another look. Journal of Vocational Behavior, 52, 156-171. 
Saxton, M., Phillips, J. S., \& Blakeney, R. N. (1991). Antecedents and consequences of emotional exhaustion in the airline reservations service sector. Human Relationships, 44, 583-595.

Schaufeli, W. B., \& Bakker, A. B. (2004a). Job demands, job resources and their relationship with burnout and engagement: A multi-sample study. Journal of Organizational Behavior, 25, 293-315.

Schaufeli, W. B., \& Bakker, A. B. (2004b). Bevlogenheid: Een begrip gemeten [Work engagement: The measurement of a concept]. Gedrag \& Organisatie, 17, 89-112.

Schaufeli, W. B., \& Enzmann, D. (1998). The burnout companion to study and research: A critical analysis. London: Taylor \& Francis.

Schaufeli, W. B., Leiter, M. P., Maslach, C., \& Jackson, S. E. (1996). Maslach burnout inventory-General survey. In C. Maslach, S. E. Jackson, \& M. P. Leiter (Eds.), The Maslach burnout inventory: test manual (3rd ed. pp. 22 26). Palo Alto, CA: Consulting Psychologists Press.

Schaufeli, W. B., \& Salanova, M. (2007a). Efficacy or inefficacy, that's the question: Burnout and work engagement, and their relationship with efficacy beliefs. Anxiety, Stress \& Coping, 20, 177-196.

Schaufeli, W. B., \& Salanova, M. (2007b). Work engagement: An emerging psychological concept and its implications for organizations. In S. W. Gilliland, D. D. Steiner, \& D. P. Skarlicki (Eds.), Research in social issues in management, Vol. 5: Managing social and ethical issues in organizations (pp. 135-177). Greenwich, CT: Information Age Publishers.

Schaufeli, W. B., Salanova, M., González-Romá, V., \& Bakker, A. B. (2002). The measurement of engagement and burnout: A confirmatory factor analytic approach. Journal of Happiness Studies, 3, 71-92.

Schaufeli, W. B., \& Taris, T. W. (2005). The conceptualization and measurement of burnout: Common ground and worlds apart. Work \& Stress, 19, 356-262.

Schaufeli, W. B., Taris, T. W., Le Blanc, P., Peeters, M., Bakker, A. B., \& De Jonge, J. (2001). Maakt arbeid gezond? Op zoek naar de bevlogen werknemer [Does work make happy? In search of the engaged worker]. De Psycholoog, 36, 422-428.

Schaufeli, W. B., \& Van Dierendonck, D. (2000). Handleiding van de Utrechtse Burnout Schaal (UBOS) [Manual Utrecht Burnout Scale]. Lisse: Swets Test Services.

Schaufeli, W. B., \& Van Rhenen, W. (2006). Over de rol van positieve en negatieve emoties bij het welbevinden van managers: Een studie met de Job-related Affective Well-being Scale (JAWS) [About the role of positive and negative emotions in managers' well-being: A study using the Job-related Affective Well-being Scale (JAWS)]. Gedrag \& Organisatie, 19, 323-244.

Schutte, N., Toppinnen, S., Kalimo, R., \& Schaufeli, W. B. (2000). The factorial validity of the Maslach burnout inventory-general survey (MBI-GS) across nations and occupations. Journal of Occupational and Organizational Psychology, 73, 53-66.

Shirom, A., Melamed, S., Toker, S., Berliner, S., \& Shapira, I. (2005). Burnout and health review: Current knowledge and future research directions. In G. P. Hodgkinson, \& J. K. Ford (Eds.), International review of industrial and organizational psychology (Vol. 20, pp. 269-309). Palo Alto, CA: Consulting Psychologists Press.

Sonnentag, S., \& Zijlstra, F. R. H. (2006). Job characteristics and off-job time activities as predictors of need for recovery, well-being, and fatigue. Journal of Applied Psychology, 91, 330-350.

Smith, P., \& Beaton, D. (2008). Measuring change in psychosocial working conditions: Methodological issues to consider when data are collected at baseline and one follow-up time point. Occupational and Environmental Medicine, 65, 288-296.

Spreitzer, G., Sutcliffe, K., Dutton, J., Sonenshein, S., \& Grant, A. M. (2005). A socially embedded model of thriving at work. Organizational Science, 16, 537-549.

Stansfeld, S., Head, J., \& Ferrie, J. (1999). Short-term disability, sickness absence, and social gradients in the Whitehall II study. International Journal of Law and Psychiatry, 22, 425-439.

Staw, B. M., Sutton, R. I., \& Pelld, L. H. (1994). Employee positive emotion and favorable outcomes at the workplace. Organizational Science, 5, 51-71.

Steel, R. P. (2003). Methodological and operational issues in the construction of absence variables. Human Resources Management Review, 13, 243-251.

Steel, R. P., \& Rentsch, J. R. (1995). Influence of cumulation strategies on the long-range prediction of absenteeism. Academy of Management Journal, 38, 1616-1634.

Storm, K., \& Rothmann, I. (2003). A psychometric analysis of the Utrecht work engagement scale in the South African police service. South African Journal of Industrial Psychology, 29, 62-70.

Tharenou, P., \& Conroy, D. (1994). Men and woman manager's advancement: Personal or situational determinants. Journal of Applied Psychology: An International Review, 43, 5-31. 
Ursin, H., Murison, R., \& Knardahl, S. (1983). Sustained activation and disease. In H. Ursin, \& R. Murison (Eds.), Biological and psychological basis of psychosomatic disease (pp. 269-277). New York: Pergamon Press.

Van Poppel, M. N., De Vet, H. C., Koes, B. W., Smid, T., \& Bouter, L. M. (2002). Measuring sick leave: A comparison of self-reported data on sick leave and data from company records. Occupational Medicine, 52, 485-490.

Van Veldhoven, M., \& Meijman, T. F. (1994). Het meten van psychosociale arbeidsbelasting met een vragenlijst: De vragenlijst beleving en beoordeling van de arbeid [The measurement of psychosocial strain at work: The questionnaire experience and evaluation of work]. Amsterdam: NIA.

Van Veldhoven, M., De Jonge, J., Broersen, S., Kompier, M., \& Meijman, T. F. (2002). Specific relations between psychosocial job conditions and job-related stress: A three-level analytic approach. Work \& Stress, 16, $207-228$.

Warr, P. B. (2007). Work, happiness and unhappiness. Mahway, NJ: Earlbaum.

Wong, C. S., Hui, C., \& Law, K. S. (1998). A longitudinal study of the job perception-job satisfaction relationship: A test of the three alternative specifications. Journal of Occupational and Organizational Psychology, 71, 127146.

Wright, T. A. (2003). Positive organizational behavior: An idea whose time has truly come. Journal of Organizational Behavior, 24, 437-442.

Wright, T. A., \& Staw, B. M. (1999). Affect and favorable work outcomes: Two longitudinal studies of the happyproductive worker thesis. Journal of Organizational Behavior, 20, 1-23.

Zapf, D., Dormann, C., \& Frese, M. (1996). Longitudinal studies in organizational stress research: A review of the literature with reference to methodological issues. Journal of Occupational Health Psychology, 1, 145-169. 